\title{
Antiproliferative effect of GTS-21 in glioblastoma cells
}

\author{
MALGORZATA A. KOLODZIEJ ${ }^{1}$, HANNA GÖTT ${ }^{1}$, BENJAMIN KOPISCHKE ${ }^{1}$, MICHAEL K.F. BENDER ${ }^{1}$, \\ MARKUS A. WEIGAND ${ }^{2}$, PIETRO DI FAZIO ${ }^{3}$, FRANK P. SCHWARM ${ }^{1 *}$ and FLORIAN UHLE ${ }^{2 *}$ \\ ${ }^{1}$ Department of Neurosurgery, Justus-Liebig University Giessen, D-35392 Giessen; \\ ${ }^{2}$ Department of Anaesthesiology, Heidelberg University Hospital, D-69120 Heidelberg; \\ ${ }^{3}$ Department of Visceral, Thoracic and Vascular Surgery, Philipps University Marburg, D-35033 Marburg, Germany
}

Received February 28, 2021; Accepted July 22, 2021

DOI: $10.3892 / \mathrm{ol} .2021 .13020$

\begin{abstract}
Glioblastoma multiforme (GBM) is the most common malignant brain tumour in adults. The poor prognosis and short median overall survival of patients with GBM is associated with resistance to therapy after surgical and adjuvant treatment. The expression of various acetylcholine receptors (AChR) in GBM has been widely reported. The present study aimed to investigate the expression of cholinergic system-related genes in primary GBM and to explore the antiproliferative effect of 3-(2,4-dimethoxybenzylidene) anabaseine (GTS-21) in GBM cell lines. Therefore, the expression of 28 genes associated with the cholinergic system was detected using a customized $\mathrm{RT}^{2}$ Profiler PCR Array in 44 GBM and 5 healthy control brain tissue samples. In addition, the activity of GTS-21, an alpha 7 subunit nicotinic AChR $(\alpha 7 \mathrm{nAChR})$ agonist, and that of $\alpha$-bungarotoxin ( $\alpha$-BTX), an $\alpha 7 \mathrm{nAChR}$ antagonist, was determined in primary and established GBM cells. Therefore, the A172, U87 and G28 cell lines and primary GBM cells were treated with GTS-21, ACh or nicotine. Cell viability was evaluated using MTT assay at 24 , 48 and $72 \mathrm{~h}$ following cell treatment with the corresponding compounds. The results revealed that the expression of cholinergic system-related components was notably downregulated, except that of cholinergic receptor nicotinic alpha 7
\end{abstract}

Correspondence to: Dr Malgorzata Anna Kolodziej, Department of Neurosurgery, Justus-Liebig University Giessen, Klinikstrasse 33, D-35392 Giessen, Germany

E-mail: malgorzata.kolodziej@neuro.med.uni-giessen.de

*Contributed equally

Abbreviations: GBM, glioblastoma multiforme; CSC, cancer stem cell; NSC, neural stem cell; Ach, acetylcholine; AChR, acetylcholine receptor; $\mathrm{nAChR}$, nicotine acetylcholine receptor; MGMT, $\mathrm{O}^{6}$-Methylguanine-DNA-methyltransferase; CHAT, choline acetyltransferase; CHRM, cholinergic receptors muscarinic; GTS-21,(3E)-3-[(2,4-dimethoxyphenyl)methylene]-3,4,5,6-tetrahydro2,3'-bipyridine; AD, Alzheimer's disease; BChE, butyrylcholinesterase

Key words: glioblastoma, 3-(2,4-dimethoxybenzylidene) anabaseine, acetylcholine receptors, bungarotoxin, nicotine receptors subunit (CHRNA7), in primary GBM and U87 cells. However, the dominant-negative duplicate form of CHRNA7 was also downregulated. Furthermore, A172 and G28 cells exhibited a heterogeneous gene expression pattern. Additionally, GTS-21 inhibited the proliferation of GBM cells in a dose- and time-dependent manner. Interestingly, treatment with $\alpha$-BTX restored the proliferation of U87 cells, but not that of A172 and G28 cells. Collectively, the findings of the present study suggested that GTS-21 may inhibit the proliferation of GBM cells and may therefore serve as a novel therapeutic approach to the treatment of GBM, which warrants further investigation.

\section{Introduction}

Glioblastoma multiforme (GBM) is the most common type of malignant tumour of the brain in adults (1). There are currently no curative treatments for this tumour entity, thus resulting in a median survival of 14 months $(1,2)$. This could be due to the heterogeneity in terms of genetic and epigenetic alterations (3), which triggers GBM tumourigenesis. Cancer stem cells may be considered as a therapeutic target for the treatment of GBM (4). Furthermore, it has been suggested that the tumour environment can maintain GBM growth, resistance to conventional therapy and immune escape $(4,5)$. Paez-Gonzalez et al suggested that neuronal networks could regulate the proliferation and differentiation of normal neural stem cells in the developed brain (6).

Although they have been recognized as crucial components of central and peripheral neurotransmission, acetylcholine $(\mathrm{ACh})$ and its receptors $(\mathrm{AChR})$ are evolutionarily conserved and are also broadly expressed in several other non-neuronal cell types, including bronchial epithelial, glial, pulmonary vascular, ovarian and cancer cells $(7,8)$.

Nicotinic AChRs (nAChRs), as the main regulators of complex inhibitory and stimulatory networks, mediate the production and release of growth, angiogenic and neurogenic factors in cancer cells $(7,9)$. Furthermore, it has been reported that nAChRs regulate the activation of intracellular signalling pathways in a cell type-specific manner (10).

Emerging evidence has suggested that alpha 7 subunit $(\alpha 7)$ nAChRs (11) regulate the cholinergic anti-inflammatory pathways $(12,13)$. Among these pathways, a study showed that ACh dose-dependently inhibited the TNF- $\alpha$ and IL- 6 pathways in human macrophages (14). $\alpha 7 \mathrm{nAChRs}$ are characterized 
by the presence of the genetically duplicated fusion gene CHRFAM7A $(15,16)$. The chimeric gene product, dup $\alpha 7$, interacts with the $\alpha 7$ subunits to form a dominant-negative and dysfunctional receptor. The hybrid, resulting from the fusion of the partial duplication of CHRNA7 with FAM7, CHRFAM7A, is expressed in the brain and peripheral tissues (15-18).

The present study aimed to investigate the role of $\mathrm{ACh}$, nicotine, $\alpha$-bungarotoxin ( $\alpha$-BTX) and 3-(2,4-dimethoxybenzylidene) anabaseine (GTS-21) in inhibiting the proliferation of primary GBM cells and GBM cell lines, namely A-172, G-28 and U-87.

\section{Materials and methods}

Patient characteristics. The data and samples of the patient sample used in our previous study were reclaimed The samples are collected between 01/2006 and 12/2012 (Departments of Neurosurgery and Neuropathology, University of Giessen, Germany) (19). At the time of diagnosis, the mean age of the 44 patients with GBM was $57.4 \pm 15.7$ years (f:m=13:31), while the progression-free survival (PFS) time of the patients was 16 months. In the present study, all cases received a gross total resection. The overall survival (OS) of patients with $M G M T$ promoter methylation was longer(OS, 23 months; range, 14.8-29.2) compared with those without $M G M T$ promoter methylation (OS, 11 months; range, 5.5-16.5) (19). Inclusion criteria was diagnosed GBM, exclusion criteria were missing consent, missing files and Karnofsky-Index $<80$. All patients provided written informed consent prior to enrolment in the study (Table I).

Chemicals and cell lines. Nicotinehydrogentatrate (cat. no. N3260) and ACh were purchased from Sigma-Aldrich (Merck KGaA). GTS-21 (cat. no. 4557) was obtained from Tocris Bioscience, while $\alpha$-BTX (cat. no. B1601) was purchased from Thermo Fisher Scientific, Inc. The A172, G28, U87 cell lines were purchased from ATCC. U87 cell line is a glioblastoma of unknown origin (HTB-14).

Tissue specimens from patients with histologically confirmed GBM were immediately collected after surgery. To isolate cells for the primary cell cultures, the tissues were finely chopped in DMEM (Dubelcco's modified Eagle's medium) and trypsinized using an $0.05 \%$ EDTA/trypsin solution. The trypsin reaction was stopped by adding $10 \mathrm{ml}$ DMEM and to obtain a single cell suspension, the minced tissues were passed through a $60-\mu \mathrm{m}$ cell strainer (Sigma-Aldrich; Merck KGaA). Subsequently, cells were washed with PBS (Phosphate buffered saline). Following centrifugation, the cell pellet was resuspended in DMEM and the cells were then seeded into $25 \mathrm{~cm}^{2}$ culture flasks (Greiner Bio-One $\mathrm{GmbH}$ ) and cultured in an incubator at $37^{\circ} \mathrm{C}$ and $5 \% \mathrm{CO}_{2}$. Then, following the appropriate number of passages, the cells were expanded to $175 \mathrm{~cm}^{2}$ flasks (Greiner Bio-One GmbH). For cell cryopreservation, the cells were first washed with PBS, centrifugated, resuspended in DMSO (Merck KGaA) and finally stored in liquid nitrogen. Frozen cells were thawed in a $37^{\circ} \mathrm{C}$-water bath and were then cultured as adherent monolayers in $25-\mathrm{cm}^{2}$ flasks. The clinicopathological characteristics of patients are listed in Table I.

RNA isolation and cDNA synthesis. For total RNA isolation from frozen specimens, the RNeasy Lipid Tissue Mini Kit ${ }^{\circledR}$
Table I. Patient characteristics.

\begin{tabular}{lc}
\hline Characteristic & Value \\
\hline Total cases, $\mathrm{n}$ & 44 \\
Age at diagnosis, years & 57.4 \\
Male, $\mathrm{n}$ & 31 \\
Female, $\mathrm{n}$ & 13 \\
Survival methylated, months & 22 \\
Survival unmethylated, months & 11 \\
Resection, $\mathrm{n}$ & 41 \\
Missing data, $\mathrm{n}$ & 3 \\
\hline
\end{tabular}

(Qiagen $\mathrm{GmbH}$ ) was used. To ensure proper tissue dissociation, the specimens were treated with a lysis reagent, provided by the kit, for $2 \mathrm{~min}$ in a bead mill at 5,000 rpm. The RNA concentration was measured with NanoDrop ${ }^{\circledR} 1000$ spectrophotometer (Thermo Fisher Scientific Inc.). cDNA synthesis was carried out using $0.5 \mu \mathrm{g}$ total RNA/sample as a template with the RT ${ }^{2}$ First Strand Kit (Qiagen $\mathrm{GmbH}$ ).

Gene expression analysis. For the simultaneous analysis of 31 genes, including 28 target genes and three housekeeping genes, namely $R P L 13 A, T B B$ and $G A P D H$, a Custom $\mathrm{RT}^{2}$ Profiler PCR Array was used, containing lyophilized primers for each target gene (CAPH12576; cat. no. 330231; Qiagen $\mathrm{GmbH})$. The analysis was carried out on the StepOnePlus quantitative PCR cycler (Thermo Fisher Scientific, Inc.) using the $\mathrm{RT}^{2} \mathrm{SYBR}^{\circledR}$-Green Mastermix (Qiagen $\mathrm{GmbH}$ ) according to the manufacturer's recommendations. For the analysis, the qPCR results from all samples were merged and uploaded into the online analysis tool provided by the manufacturer. The online tool calculates the $\Delta \Delta \mathrm{Cq}$-based fold change in the expression of each target gene normalized to that of the housekeeping genes.

MTT assay. To evaluate cell survival and proliferation, a MTT assay was performed following treatment of cells with GTS-21 (Tocris Bioscience), ACh or nicotine (both from Sigma-Aldrich; Merck KGaA). Briefly, cells were seeded into 96-well plates at a density of $10^{4}$ cells/well. All cell lines were treated with $6.25,12.5,25$ or $50 \mu \mathrm{M}$ GTS-21, ACh or nicotine. The negative control cells for the GTS-21 group were treated with $0.1 \%$ DMSO, while those of the ACh and nicotine groups with $0.1 \% \mathrm{H}_{2} \mathrm{O}$. The MTT reagent (Sigma-Aldrich; Merck $\mathrm{KGaA}$ ) was diluted in DMEM at a ratio of 1:10. Following treatment of cells with the corresponding compounds for 24 , 48 and $72 \mathrm{~h}$, the culture medium was removed and the cells were supplemented with $200 \mu \mathrm{l}$ of MTT-DMEM solution and incubated at $37^{\circ} \mathrm{C}$ in an atmosphere of $95 \%$ air and $5 \% \mathrm{CO}_{2}$ for an additional $90 \mathrm{~min}$. Subsequently, the cells were lysed in $150 \mu 1$ isopropanol/hydrochloric acid solution (Sigma-Aldrich; Merck $\mathrm{KGaA}$ ) for $15 \mathrm{~min}$ and the absorbance value in each well was measured using a microplate reader at a wavelength of $562 \mathrm{~nm}$, with a reference wavelength of $630 \mathrm{~nm}$.

Statistical analysis. Statistical analysis was implemented using SPSS 20 (IBM Corp.). The comparison of different 
A

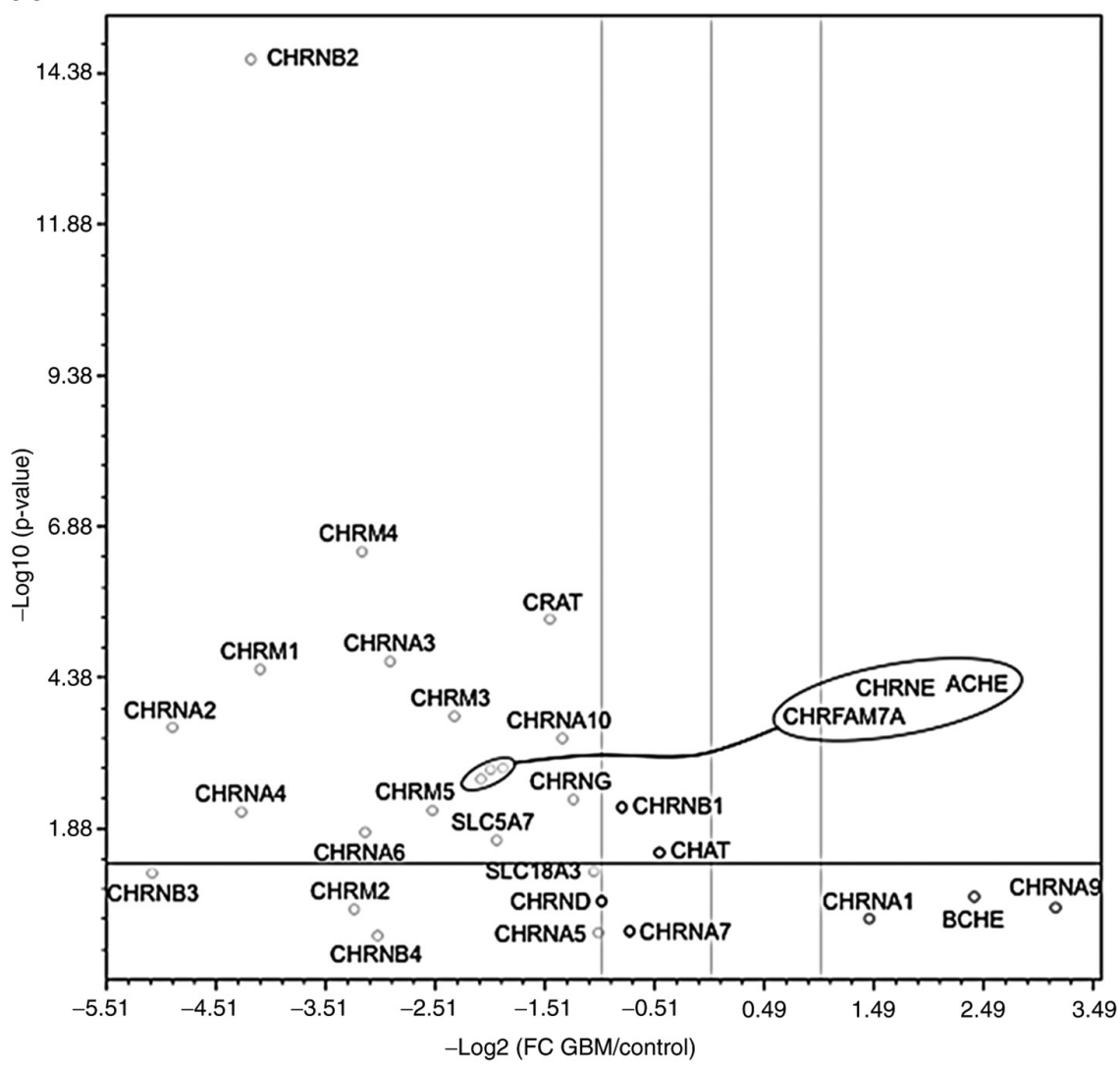

B

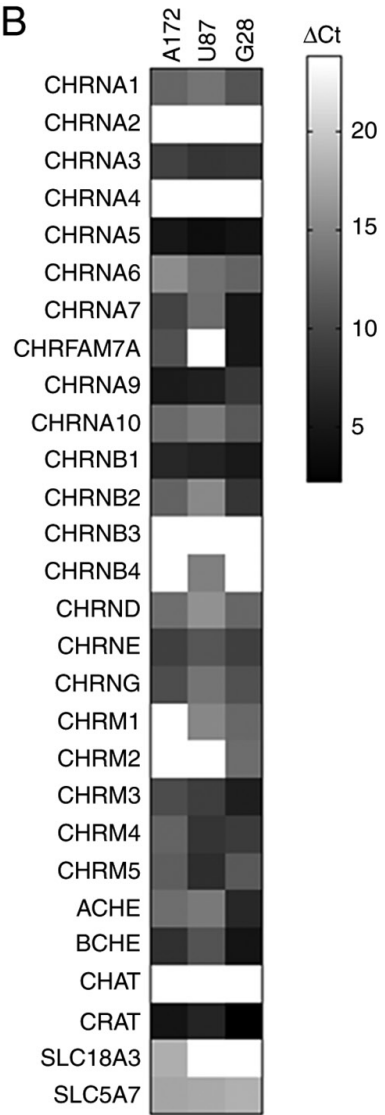

Figure 1. Gene expression of the cholinergic system in primary GBM tissue and cell lines. (A) Volcano plot visualization of the comparison of GBM $(n=44)$ vs. healthy tissue $(n=5)$. The blue horizontal line represents the P-value threshold of 0.01 . Vertical lines represent the log 2 fold change threshold of $-1 / 1$ respectively, with no change indicated by the middle line. (B) Heat map visualization of the normalized $\Delta \Delta \mathrm{Cq}\left[\mathrm{Cq} \mathrm{gene} \mathrm{of} \mathrm{interest}-\mathrm{mean}\left(\mathrm{Cq} \mathrm{GAPDH}_{\mathrm{GP}}+\mathrm{Cq} \mathrm{TBP}_{\mathrm{TBP}}+\mathrm{Cq} \mathrm{RPL}_{\mathrm{RA}}\right)\right]$ cholinergic system gene expression levels in A172, U87 and G28 cell lines. A lower value of $\Delta \Delta \mathrm{Cq}$ indicates a high expression and vice versa. GBM, glioblastoma multiforme. Red indicates upregulated genes and green represents downregulated genes.

concentrations of GTS-21 and $\alpha$-bungarotoxin were performed using Kruksal-Wallis-test (post hoc: Bonferroni). $\mathrm{P}<0.05$ was considered to indicate a statistically significant difference. Data are presented as the mean \pm SEM.

\section{Results}

Cholinergic system-related gene expression is markedly deregulated in GBM. Using a custom-made qPCR array covering the majority of components of the cholinergic system, the expression levels of these genes were assessed in 44 tissue samples obtained from patients with primary GBM and compared with those in five tissue samples from healthy subjects (Fig. 1A). The results demonstrated that the expression of the majority of genes encoding the receptor subunits was significantly downregulated (fold changes, $\log _{2}$ $>-1 ; \mathrm{P}<0.01)$. Additionally, the gene expression levels of $A C H E$ and those of the dominant-negative form of $C H R N A 7$ and the duplicate fusion gene product of $C H R F A M 7 A$ were also significantly suppressed. In addition, the expression levels of three genes, namely $C H R N B 1$, encoding the nicotinic $\beta 1$ receptor subunit, $C H A T$, encoding choline acetyltransferase and $C H R N A 7$, encoding the nicotinic $\alpha 7$ receptor subunit, remained unchanged.

The expression levels of the cholinergic system-related genes were also determined in the established GBM cell lines
A172, U87 and G28 (Fig. 1B). CHRNA2 was not expressed in any of the three cell lines examined. By contrast, CHRNA1, CHRNA9 and BCHE were expressed in all cell lines. The most significant differences in the gene expression profile between primary GBM cells and cell lines were observed in CHAT expression, as CHAT was not expressed in A172, U87 and $\mathrm{G} 28$ cells compared with primary GBM cells. This finding could be attributed to the loss of ACh synthesis. Despite the similarities, the cell lines exhibited quantitative and qualitative heterogeneity in the expression of several genes, including CHRM2, which was expressed in G28, but not in A172 and U87 cells and the fusion gene product CHRFAM7A, which was not expressed in U87 cells.

Overall, the aforementioned findings revealed significant differences in the expression of cholinergic system-related genes in GBM. More specifically, the expression of CHRNA7 remained unchanged in all cell lines examined, indicating that these cell lines may serve as important tools for evaluating the role of CHRNA7 in GBM. Furthermore, the heterogeneity in the expression of CHRFAM7A could contribute to a better understanding of the participation of the dominant-negative regulator in the cholinergic system.

GTS-21, but no other cholinergic agonists, inhibits GBM cell proliferation. Subsequently, the present study aimed to investigate the effect of the activation of the $\alpha 7$-composed 

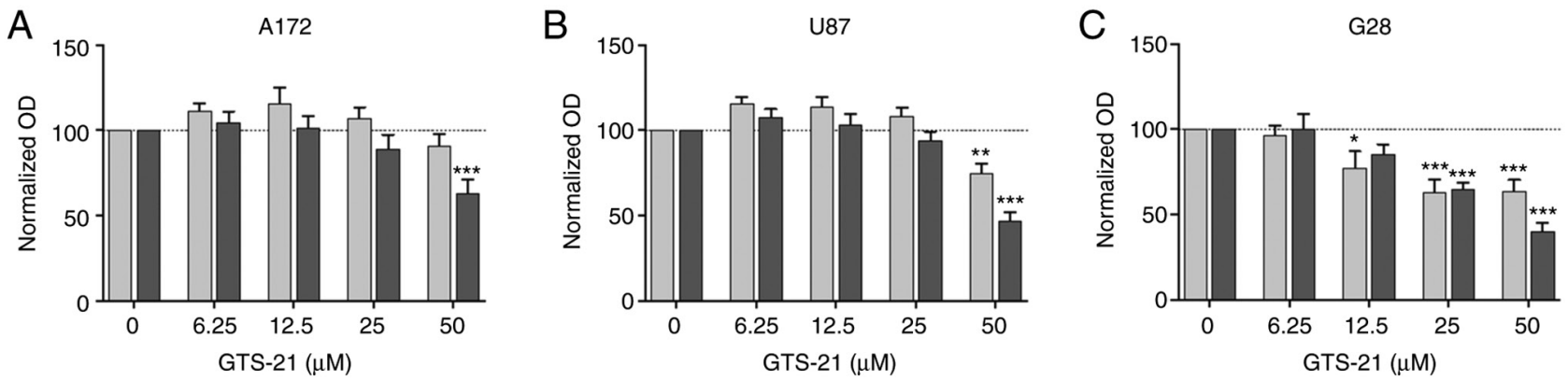

Figure 2. GTS-21 impairs glioblastoma multiforme cell line proliferation in a time- and dose-dependent manner. (A) A172, (B) U87 and (C) G28 cells were incubated with different concentrations of GTS-21 for $24 \mathrm{~h}$ (light grey) or $48 \mathrm{~h}$ (dark grey). The MTT assay was performed afterwards and individual values were normalized to the DMSO treated control group. The horizontal line depicts the baseline. Data are presented as the mean \pm SEM $(n=5){ }^{*} \mathrm{P}<0.05$, ${ }^{* *} \mathrm{P}<0.01$ and ${ }^{* * * *} \mathrm{P}<0.001$ vs. the DMSO treated group. GTS-21, 3-(2,4-dimethoxybenzylidene) anabaseine; OD, optical density.
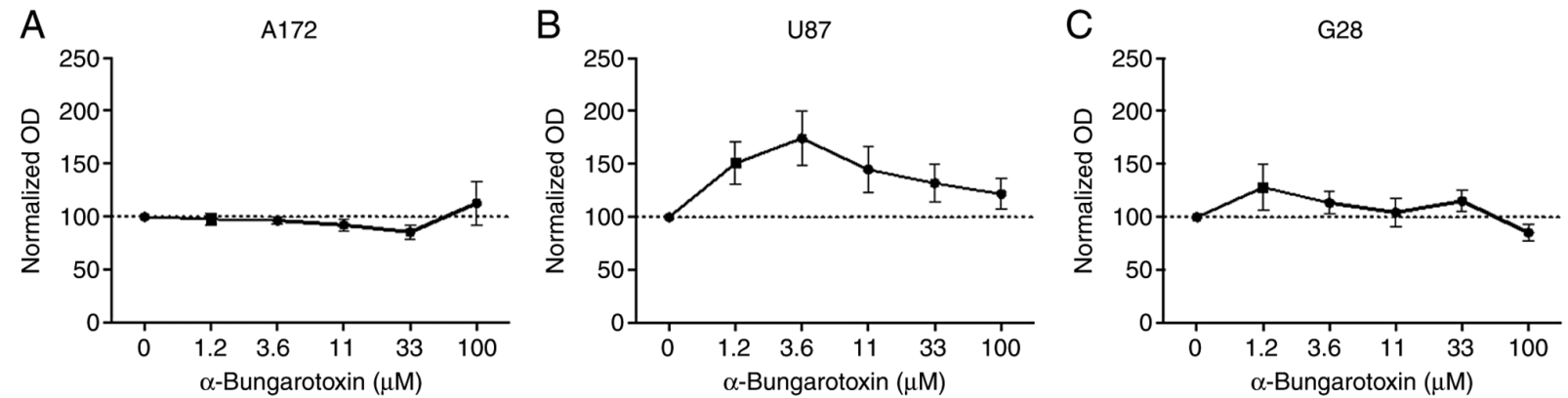

Figure 3. Coincubation with $\alpha$-bungarotoxin reestablishes the proliferation of GTS-21 treated U87 cells. (A) A172, (B) U87 and (C) G28 cells were incubated with increasing concentrations (1.2-100 $\mu \mathrm{M})$ of $\alpha$-bungarotoxin in the presence of GTS-21 (50 $\mu \mathrm{M})$. An MTT assay was subsequently performed and individual values were normalized to that of the untreated control group. Data are presented as the mean \pm SEM $(n=4)$. GTS-21, 3-(2,4-dimethoxybenzylidene) anabaseine; OD, optical density.

nAChR on cellular proliferation. Therefore, the three GBM cell lines A172, U87 and G28 were stimulated with increasing concentrations of GTS-21, a well-known partial agonist of $\alpha 7$ and $\alpha 4 \beta 2$ subunits, for 24 and $48 \mathrm{~h}$. Since both $\alpha 4$ and $\beta 2$ subunits were not expressed in the current cell model, GTS-21 served as a sole $\alpha 7$ agonist. Cell treatment with $50 \mu \mathrm{M}$ GTS-21 significantly attenuated the proliferation of all cell lines at $48 \mathrm{~h}$ (Fig. 2). However, the extent of reduction differed among the different GBM cell lines (A172 cells, 63.3 $\pm 7.5 \%$; G28 cells, $39.4 \pm 5.3 \%$; U87 cells, 47.2 $\pm 4.8 \%$ ). Additionally, GTS-21 exerted an antiproliferative effect on G28 cells even after treatment with $12.5 \mu \mathrm{M}$ GTS-21 for $24 \mathrm{~h}$ (Fig. 2C). However, treatment of cells with equimolar concentrations of cholinergic agonists, namely nicotine and $\mathrm{ACh}$, had no effect on cell viability (Fig. S1). In summary, pharmacological stimulation of the $\alpha 7$ receptor subunits with GTS-21 reduced GBM cell proliferation.

$\alpha 7$ subunit affects the antiproliferative capacity of GTS-21. To investigate whether the antiproliferative effect of GTS-21 was associated with the $\alpha 7$ subunit, GBM cells were co-treated with $50 \mu \mathrm{M}$ GTS-21 and increasing concentrations of $\alpha$-BTX (1.2-100 $\mu \mathrm{M})$, an antagonist of the homo-pentameric $\alpha 7$ receptor, for $48 \mathrm{~h}$. The results showed that treatment of A172 and G28 cells with $\alpha$-BTX had no effect on their proliferation capacity (Fig. 3A and C). However, the proliferation rate of U87 cells treated with $3.6 \mu \mathrm{M} \alpha$-BTX was notably increased (174.6 $\pm 21.71 \%$; Fig. 3B). This finding indicated that the

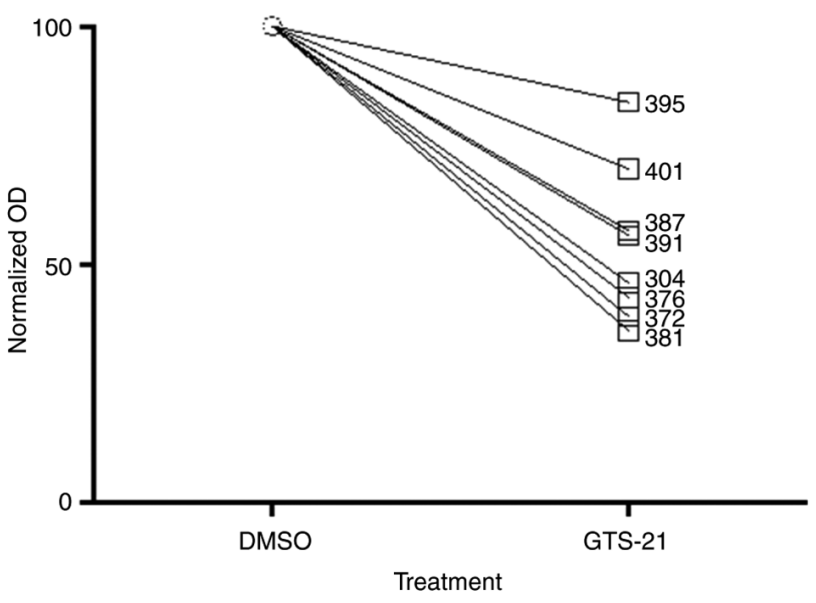

Figure 4. GTS-21 treatment inhibits proliferation of cultured primary GBM cells. A total of 8 primary GBM cell lines $(395,401,387,391,304,376$, 372 and 381) were treated with GTS-21 $(50 \mu \mathrm{M})$ for $48 \mathrm{~h}$, after which cell proliferation was assessed using an MTT assay. The OD of each sample was normalized to the corresponding DMSO-treated control sample. Data are presented as the mean \pm SEM $(n=4)$. GBM, glioblastoma multiforme; GTS-21, 3-(2,4-dimethoxybenzylidene).

proliferative effects of GTS- 21 could be abolished by $\alpha$-BTX only in U87 cells.

GTS-21 inhibits the proliferation of primary GBM cells. A total of eight primary GBM cell cultures were treated with 
$6.25,12.5,25$ or $50 \mu \mathrm{M}$ GTS-21 for $48 \mathrm{~h}$. The proliferation rate of primary tumour cells treated with different doses of GTS-21 was significantly reduced compared with A172, G28 and U87 cells (Fig. 4), suggesting that all primary cells responded to treatment. The median inhibition rate (loss of proliferation) in primary GBM cells was 51\%, ranging between 36 and $84 \%$.

\section{Discussion}

Normal brain function depends on the presence and interaction between diverse neurotransmitters and neuropeptides. Emerging evidence has demonstrated that neuropeptides and neurotransmitters, as well as their cognate receptors, are expressed by astrocytes (20). Therefore, the ligand-receptor-mediated cellular responsiveness could also be considered as an adjunctive therapy approach to GBM. However, persistent invasiveness and resistance to standard therapy remain the major challenges in the development of more effective treatment options for GBM.

Nevertheless, novel therapies are urgently needed to improve PFS and OS of patients with GBM. Bavo et al (21) showed that the activation of $\mathrm{nAChR}$, composed of $\alpha 7$ and $\alpha 9 \alpha 10$ subunits, could promote GBM cell proliferation. Another study demonstrated that the decreased expression levels of CHRFAM7A were associated with the onset of Alzheimer's disease, supporting its role in pathological conditions. By contrast, CHRFAM7A was upregulated in schizophrenia and bipolar disorders (11). Furthermore, previous study $(17,22)$ demonstrated that $C H R F A M 7 A$ was a stoichiometric dominant-negative regulator of a7 nAChR. Instead, no mutations have been identified in GBM occurring at the CHRNA7 loci, supporting its normal expression in these cancer cells (23). To the best of our knowledge, the current study was the first to investigate the effect of $C H R N A 7$, encoding $\alpha 7 \mathrm{nAChR}$, and CHRFAM7A on three GBM cell lines, GBM tissues and normal brain tissues (control).

Pucci et al (24) reported the effect of $\alpha 7 \mathrm{nAChR}$ on the proliferation of GBM cells. In the current study, the potential role of GTS-21 as a partial agonist of $\alpha 7 \mathrm{nAChR}$ was investigated in GBM cell lines. The results revealed that the proliferation ability of all cell lines was significantly attenuated following treatment with GTS-21. However, the optimal concentration for inhibiting the cell proliferation differed among the three cell lines tested, with G28 cells being the most sensitive, since G28 cells showed the highest expression of CHRFAM7A. Interestingly, antagonizing the aforementioned strong effect by means of cell treatment with $\alpha$-BTX, showed that the cell proliferation was only restored in U87 cells, possibly due to a lack of $C H R F A M 7 A$ expression.

Furthermore, the expression of CHRNA1 and CHRNA9, encoding the a1 and a9 subunits of $\mathrm{nAChR}$, and that of $B C H E$, encoding the ACh-degrading enzyme, butyrylcholinesterase, was notably upregulated. This finding confirmed the previously reported findings, showing that GBM cells could express the $\alpha 7$ and $\alpha 9 \alpha 10$ subunits of nAChRs (21). A previous study also demonstrated that CHRNAI and CHRNA9 upregulation was associated with shorter OS in patients with GBM (10).

The results suggested that the upregulation of $\alpha 7 \mathrm{nAChR}$ in heterologous cell lines could suppress the cell proliferation.
It has been reported that $\alpha 7 \mathrm{nAChR}$ is upregulated in the GBM vessel endothelium, GBM cells and tumour-associated macrophages, thus suggesting that $\alpha 7 \mathrm{nAChR}$ could be a potential target for the treatment of GBM (25). However, the effect of GTS-21 was only abrogated in U87 cells, which did not express CHRFAM7A, following treatment with $\alpha$-BTX, suggesting that GTS-21 could act in an $\alpha 7$ nAChR-independent manner.

The limitation of our study is absence of data related to TERT and IDH mutation and very small population.

In conclusion, the present study showed that GBM cell treatment with GTS-21, an agonist of the $\alpha 7$ receptor, attenuated their proliferation. However, treatment with $\alpha$-BTX restored the proliferation of U87 cells pre-treated with GTS-21. These findings suggested that GTS-21 may be considered as a novel treatment approach to GBM, due to its $\alpha 7 \mathrm{nAChR}$-independent mechanism of action. However, further in vivo studies are required to elucidate the underlying mechanism of action and potential therapeutic application of GTS-21.

\section{Acknowledgements}

Not applicable.

\section{Funding}

No funding was received.

\section{Availability of data and materials}

The datasets used and/or analyzed during the current study are available from the corresponding author on reasonable request.

\section{Authors' contributions}

MAK designed the current study, wrote and reviewed the data and literature of the manuscript, and analyzed the data. BK collected and analyzed the data. FU performed statistical analysis and reviewed the data and literature of the manuscript. MAW and MKFB analyzed the data. PDF analyzed the data, performed statistical analysis and reviewed the data and literature of the manuscript. FPS and HG designed the current study and reviewed the data and literature of the manuscript. All authors read and approved the final manuscript.MAK and FU confirm the authenticity of all the raw data.

\section{Ethics approval and consent to participate}

The current study was approved by the local Ethics Committee Justus-Liebig-University Giessen (application no. AZ 07/09). All research followed the international and national regulations in accordance with the Declaration of Helsinki.

\section{Patient consent for publication}

Not applicable.

\section{Competing interests}

The authors declare that they have no competing interests. 


\section{References}

1. Krex D, Klink B, Hartmann C, von Deimling A, Pietsch T, Simon M, Sabel M, Steinbach JP, Heese O, Reifenberger G, et al: Long-term survival with glioblastoma multiforme. Brain 130: 2596-2606, 2007.

2. Stupp R, Mason WP, van den Bent MJ, Weller M, Fisher B, Taphoorn MJ, Belanger K, Brandes AA, Marosi C, Bogdahn U, et al Radiotherapy plus Concomitant and Adjuvant Temozolomide for Glioblastoma. N Engl J Med 352: 987-996, 2005.

3. Maher EA: Malignant glioma: Genetics and biology of a grave matter. Genes Dev 15: 1311-1333, 2001.

4. Bonavia R, Inda MM, Cavenee WK and Furnari FB: Heterogeneity maintenance in glioblastoma: A social network. Cancer Res 71: 4055-4060, 2011.

5. Hadjipanayis CG and Van Meir EG: Brain cancer propagating cells: Biology, genetics and targeted therapies. Trends Mol Med 15: 519-530, 2009.

6. Paez-Gonzalez P, Asrican B, Rodriguez E and Kuo CT: Identification of distinct $\mathrm{ChAT}^{+}$neurons and activity-dependent control of postnatal SVZ neurogenesis. Nat Neurosci 17: 934-942, 2014.

7. Kuol N, Stojanovska L, Apostolopoulos V and Nurgali K: Role of the nervous system in tumor angiogenesis. Cancer Microenviron 11: 1-11, 2018.

8. Li ZZ, Wang YL, Yu YH, Xing YL and Ji XF: Aclidinium bromide inhibits proliferation of osteosarcoma cells through regulation of PI3K/Akt pathway. Eur Rev Med Pharmacol Sci 23: $105-112,2019$.

9. Wessler I and Kirkpatrick CJ: Acetylcholine beyond neurons: The non-neuronal cholinergic system in humans. Br J Pharmacol 154: 1558-1571, 2008.

10. Spina R, Voss DM, Asnaghi L, Sloan A and Bar EE: Atracurium Besylate and other neuromuscular blocking agents promote astroglial differentiation and deplete glioblastoma stem cells. Oncotarget 7: 459-472, 2016.

11. Pohanka M: Alpha7 nicotinic acetylcholine receptor is a target in pharmacology and toxicology. Int J Mol Sci 13: 2219-2238, 2012.

12. Shytle RD, Mori T, Townsend K, Vendrame M, Sun N, Zeng J, Ehrhart J, Silver AA, Sanberg PR and Tan J: Cholinergic modulation of microglial activation by alpha 7 nicotinic receptors. J Neurochem 89: 337-343, 2004.

13. Pavlov VA and Tracey KJ: The cholinergic anti-inflammatory pathway. Brain Behav Immun 19: 493-499, 2005.

14. Rosas-Ballina M and Tracey KJ: Cholinergic control of inflammation. J Intern Med 265: 663-679, 2009.

15. Gault J, Robinson M, Berger R, Drebing C, Logel J, Hopkins J, Moore T, Jacobs S, Meriwether J, Choi MJ, et al: Genomic organization and partial duplication of the human alpha7 neuronal nicotinic acetylcholine receptor gene (CHRNA7). Genomics 52: 173-185, 1998.
16. Sinkus ML, Graw S, Freedman R, Ross RG, Lester HA and Leonard S: The human CHRNA7 and CHRFAM7A genes: A review of the genetics, regulation, and function. Neuropharmacology 96: 274-288, 2015.

17. de Lucas-Cerrillo AM, Maldifassi MC, Arnalich F, Renart J, Atienza G, Serantes R, Cruces J, Sánchez-Pacheco A, AndrésMateos E and Montiel C: Function of partially duplicated human $\alpha 77$ nicotinic receptor subunit CHRFAM7A gene: Potential implications for the cholinergic anti-inflammatory response. J Biol Chem 286: 594-606, 2011.

18. Locke DP, Archidiacono N, Misceo D, Cardone MF, Deschamps S, Roe B, Rocchi M and Eichler EE: Refinement of a chimpanzee pericentric inversion breakpoint to a segmental duplication cluster. Genome Biol 4: R50, 2003.

19. Kolodziej MA, Weischer C, Reinges MHT, Uhl E, Weigand MA, Schwarm FP, Schänzer A, Acker T, Quint K, Uhle F and Stein M: NDRG2 and NDRG4 Expression Is Altered in Glioblastoma and Influences Survival in Patients with MGMT-methylated Tumors. Anticancer Res 36: 887-897, 2016.

20. Murphy S and Pearce B: Functional receptors for neurotransmitters on astroglial cells. Neuroscience 22: 381-394, 1987.

21. Bavo F, Pucci S, Fasoli F, Lammi C, Moretti M, Mucchietto V, Lattuada D, Viani P, De Palma C, Budriesi R, et al: Potent antiglioblastoma agents by hybridizing the onium-alkyloxy-stilbene based structures of an $\alpha 7-n A C h R, \alpha 9-n A C h R$ antagonist and of a pro-oxidant mitocan. J Med Chem 61: 10531-10544, 2018.

22. Araud T, Graw S, Berger R, Lee M, Neveu E, Bertrand D and Leonard S: The chimeric gene CHRFAM7A, a partial duplication of the CHRNA7 gene, is a dominant negative regulator of $\alpha 7 *_{n}$ AChR function. Biochem Pharmacol 82: 904-914, 2011.

23. Brennan CW, Verhaak RGW, McKenna A, Campos B, Noushmehr H, Salama SR, Zheng S, Chakravarty D, Sanborn JZ, Berman SH, et al: The somatic genomic landscape of glioblastoma. Cell 155: 462-477, 2013.

24. Pucci S, Fasoli F, Moretti M, Benfante R, Di Lascio S, Viani P, Daga A, Gordon TJ, McIntosh M, Zoli M, et al: Choline and nicotine increase glioblastoma cell proliferation by binding and activating $\alpha 7$ - and $\alpha 9$ - containing nicotinic receptors. Pharmacol Res 163: 105336, 2021.

25. Zheng Z, Zhang J, Jiang J, He Y, Zhang W, Mo X, Kang X, $\mathrm{Xu} \mathrm{Q}$, Wang B and Huang Y: Remodeling tumor immune microenvironment (TIME) for glioma therapy using multi-targeting liposomal codelivery. J Immunother Cancer 8: e000207, 2020. 